\title{
Pain and disability following fusion for idiopathic adolescent scoliosis: prevalence and associated factors
}

Authors Teresa Bas ${ }^{1}$, Nuria Franco ${ }^{2}$, Paloma Bas ${ }^{1}$, Jose Luis Bas ${ }^{3}$

Institutions $\quad{ }^{1}$ Spinal Service, Hospital Universitario y Politécnico La Fe, Valencia, Spain

${ }^{2}$ Hospital de Denia, Alicante, Spain

${ }^{3}$ Hospital General De Castellón, Castellón, Spain

\begin{tabular}{|c|c|}
\hline \multicolumn{2}{|l|}{$\begin{array}{l}\text { Final class of } \\
\text { evidence-prognosis }\end{array}$} \\
\hline \multicolumn{2}{|l|}{ Study design } \\
\hline \multicolumn{2}{|l|}{ Prospective Cohort } \\
\hline Retrospective Cohort & 。 \\
\hline \multicolumn{2}{|l|}{ Case control } \\
\hline \multicolumn{2}{|l|}{ Case series } \\
\hline \multicolumn{2}{|l|}{ Methods } \\
\hline $\begin{array}{l}\text { Patients at similar point in } \\
\text { course of treatment }\end{array}$ & - \\
\hline$F / U \geq 85 \%$ & \\
\hline $\begin{array}{l}\text { Similarity of treatment } \\
\text { protocols for patient groups }\end{array}$ & \\
\hline $\begin{array}{l}\text { Patients followed up long } \\
\text { enough for outcomes to occur }\end{array}$ & $\cdot$ \\
\hline $\begin{array}{l}\text { Control for extraneous risk } \\
\text { factors }\end{array}$ & ॰* \\
\hline Overall class of evidence & III \\
\hline \multicolumn{2}{|l|}{$\begin{array}{l}\text { The definiton of the different } \\
\text { classes of evidence is available } \\
\text { on page } 55 .\end{array}$} \\
\hline \multicolumn{2}{|c|}{$\begin{array}{l}\text { * Potentially confounding factors } \\
\text { were systematically explored and } \\
\text { considered for stratified analysis } \\
\text { as appropriate. }\end{array}$} \\
\hline
\end{tabular}

\section{ABSTRACT}

Study design: Retrospective prognostic study.

Objectives: To describe the prevalence of pain following fusion for adolescent idiopathic scoliosis and to identify factors associated with pain and disability.

Methods: From 126 consecutive patients surgically treated for scoliosis between 1997 and 2007, 104 (82.5\%) completed SRS-22 and ODI questionnaires at a last follow-up (mean, 4.8 years; range $1-11.2$ years). Prevalence of pain and disability were determined from SRS questions 1 and 9 respectively, with "any" pain or decrease in activity considered clinically significant. SRS Pain Domain Scores (PDS) were also evaluated.

Results: Most participants reported "no pain" (38.5\%) or "mild pain" (30.8\%) and $72.1 \%$ of participants reported a current work/school activity level of $100 \%$ normal. An association between instrument type and the presence of any pain in the previous 6 months was noted $(P=.022)$. Instrument type was the only factor that was significantly associated with the PDS $(P=.0052)$.

Conclusions: The high percentage of patients reporting no pain or mild pain may suggest overall success of the procedures. Although an association between instrument type and pain was seen, unmeasured factors that contributed to the decision of what instrument to use may confound the relationship. From these data a causal inference cannot be made. 


\section{STUDY RATIONALE AND CONTEXT}

Outcome measures after surgery for adolescent idiopathic scoliosis (AIS) have focused mainly on objective parameters, such as radiographic changes. However, radiographic outcomes following surgical treatment of AIS have been only weakly correlated with patient-reported outcomes measuring functional status and symptoms [1,2]. Use of disease-specific, validated questionnaires provides significant information regarding factors that are important to patient quality of life following fusion [3-5].

A common concern among surgeons performing scoliosis procedures is whether spinal fusion will reduce function in young patients. Also, results presented are not conclusive regarding effects on back pain and its correlation to a fusion extending into the lower lumbar spine. This is why outcome studies, focusing on mid-term and longterm impairments as primary effect variables, are critically needed.

Most of the long-term results in the literature were obtained using the Harrington rod system, there are however few, if any, such studies featuring segmental instrumentation systems. This was our main reason for deciding to study pain and disability using segmental hybrid instrumentation for patients with AIS.

\section{OBJECTIVES}

To describe the prevalence of pain following fusion for AIS and to identify factors associated with greater pain or disability.

Fig 1 Patient sampling and selection.

Total patients receiving intervention during time period $(n=142)$

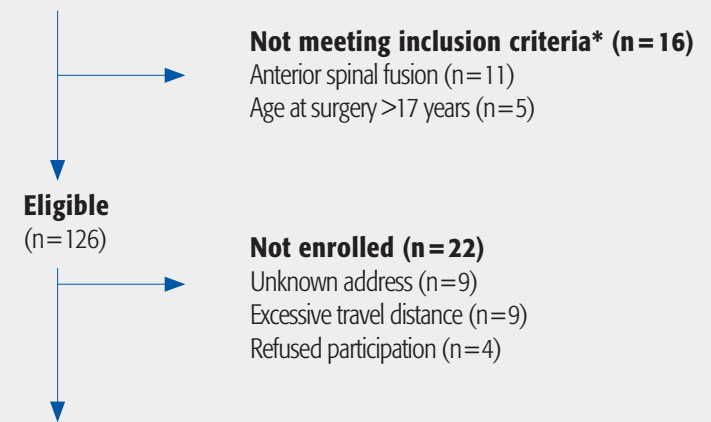

Patients available for analysis $(n=104)$

$$
\text { *Percentage follow-up }=82.5 \% \text {. }
$$

\section{METHODS}

Study design: Retrospective prognostic study.

Inclusion criteria: All subjects $(\mathrm{N}=142)$ with AIS who underwent spinal fusion between January 1, 1997, and December 31, 2007, at our hospital were potentially eligible.

Exclusion criteria: Patients who had anterior fusion $(n=11)$ or were older than 17 years $(n=5)$ were excluded, leaving 126 consecutive patients eligible.

\section{Patient population and selection (Fig 1):}

From 126 consecutive patients who were eligible, 104 were available for analysis. Of the 22 patients lost to follow-up, the patient's address was unknown $(n=9)$, patient refused to participate $(n=4)$, or traveling distance was excessive $(n=9)$. The percentage of follow-up was $82.5 \%$ (104/126). Choice of fixation device was made based on surgeon preference and was not based on type or severity of deformity.

Outcomes: Questions 1 and 9 of the SRS-22 were used to determine prevalence of pain (in the past 6 months) and disability, respectively. The SRS Pain Domain Score (PDS) was evaluated as an outcome to facilitate comparison with other published studies and further evaluate factors associated with pain.

\section{Risk factors and potentially confounding factors} evaluated:

- Demographic factors: gender, age at surgery, age at follow-up, follow-up time

- Clinical factors: curve type

- Procedural factors: surgical approach, types of instrument, lowest instrumented level

- Complications as risk factors for pain: reoperation, infection, implant failure, dislodging of hook, correction loss, pseudarthrosis, number of levels fused

Analysis: To evaluate associations between "any" pain or disability and potential risk factors, responses were dichotomized to reflect "no pain" and "no disability" (response of five to the questions) and "any" pain or disability (responses 1-4) and chi-square test or Fisher exact test (if cells contained fewer than five individuals) were performed. The Kruskall-Wallis test using the SRS PDS as a continuous outcome variable was done to compare medians among two or more groups for the categorical variables. Spearman's correlation was done to evaluate associations between PDS and continuous variables. All statistical tests were two-tailed. Stratified 
analysis was explored to control for potential confounding when feasible and appropriate.

Additional information is available in the web appendix at $w w w$.aospine.orglebsj.

\section{RESULTS}

- Most patients $(87.5 \%)$ were female, the mean age at time of surgery was 14.9 years (range, 12-17 years) and mean age at follow-up was 19.6 years (range, 13-27 years). The most common curve types were Lenke types $1(48.1 \%)$ and $3(40.4 \%)$. The Universal Spine System (USS-Synthes, Paoli, PA, USA) was used most frequently with a mean of 11 levels fused (Table 1).

- Most participants reported "no pain" (38.5\%) or "mild pain" $(30.8 \%)$ with only seven patients $(6.7 \%)$ reporting moderate to severe or severe pain in the previous 6 months (Fig 2).

- $72.1 \%$ of participants reported a current work/school activity level of $100 \%$ normal; $20.2 \%$ reported current level of 75\% normal (Fig 3).

- The association between presence of any pain in the previous 6 months and gender was not significant $(P=.067)$. Superficial infection, which occurred in five patients (with four patients marking the response "any" pain on Q1) was not significantly involved with complaints of pain $(P=.074)$.

- Furthermore, there was no association between pain in the previous 6 months and any other covariable (Table 2).

- Instrumentation type was the only factor that was significantly associated with a positive PDS in a single implant system $(P=.022)$ (Table 3).

- The mean scores for individual SRS domains were all above $\geq 4.0$ (of a possible 5.0) (Table 4).
Table 1 Patient characteristics and prognostic factors.

\begin{tabular}{ll}
\hline Demographics & $\mathbf{N}=\mathbf{1 0 4}$ \\
\hline Mean age at time of surgery (range), y & $14.9(12-17)$ \\
\hline Mean age at final follow-up (range), y & $19.6(13-27)$ \\
\hline Female, No. (\%) & $91(87.5)$ \\
\hline Clinical factors &
\end{tabular}

Follow-up, mean (range), y

$4.8(1-11.2)$

Follow-up, №. (\%)

$\leq 2 y \quad 29(27.9)$

$2-5 y \quad 38(36.5)$

$>5 \mathrm{y} \quad 37$ (35.6)

Lenke curve type, No. (\%)

$\begin{array}{ll}\text { Type } 1 & 50(48.1)\end{array}$

Type 2

Type $3 \quad 42(40.4)$

Type $4 \quad 1(1.0)$

Type 5

Missing 4 (3.8)

Radiographic parameters, mean (range**

Preoperative main curve $\quad 52^{\circ}\left(48^{\circ}-89^{\circ}\right)$

Postoperative main curve $\quad 32^{\circ}\left(13^{\circ}-63^{\circ}\right)$

Percentage of correction 52\% (44\%-67\%)

Postoperative thoracic kyphosis $25^{\circ}\left(8^{\circ}-50^{\circ}\right)$

Postoperative lumbar lordosis $\quad 40^{\circ}\left(5^{\circ}-72^{\circ}\right)$

\begin{tabular}{ll}
\hline Procedural factors & \\
\hline Total levels fused, mean (range) & $11.1(8-14)$ \\
\hline Posterior spinal fusion, No. (\%) & $89(85.6)$
\end{tabular}

Type of instrumentation, №. (\%)

USS

$32(30.8)$

Colorado $24(23.1)$

TSRH $16(15.4)$

Transpine $14(13.5)$

ISOLA $6(5.8)$

Synergy $7(6.7)$

Missing $5(4.8)$

Lowest instrumented level, No. (\%)

$\mathrm{T} 11$

$\mathrm{T} 12$

L1 $27(26)$

L2 $28(27)$

L3 $29(28)$

L4 11 (10)

Complications, No. (\%)

Reoperation

$7(6.7)$

Pseudarthrosis $^{\dagger} \quad 11(10.6)$

- Implant failure 4 (3.8)

- Frontal plane correction loss $>15^{\circ}$

Infection

- Superficial (early) 5 (4.8)

- Deep (late) 1. (0.96)

Dislodgement of rostral or caudal hook 3 (2.9)

* Less than $10 \%$ of values were estimated to be missing.

† Patients with either implant failure or correction loss are included in this category. 
Fig 2 Amount of pain in the last 6 months-(Which best describes the amount of pain during the past 6 months?)

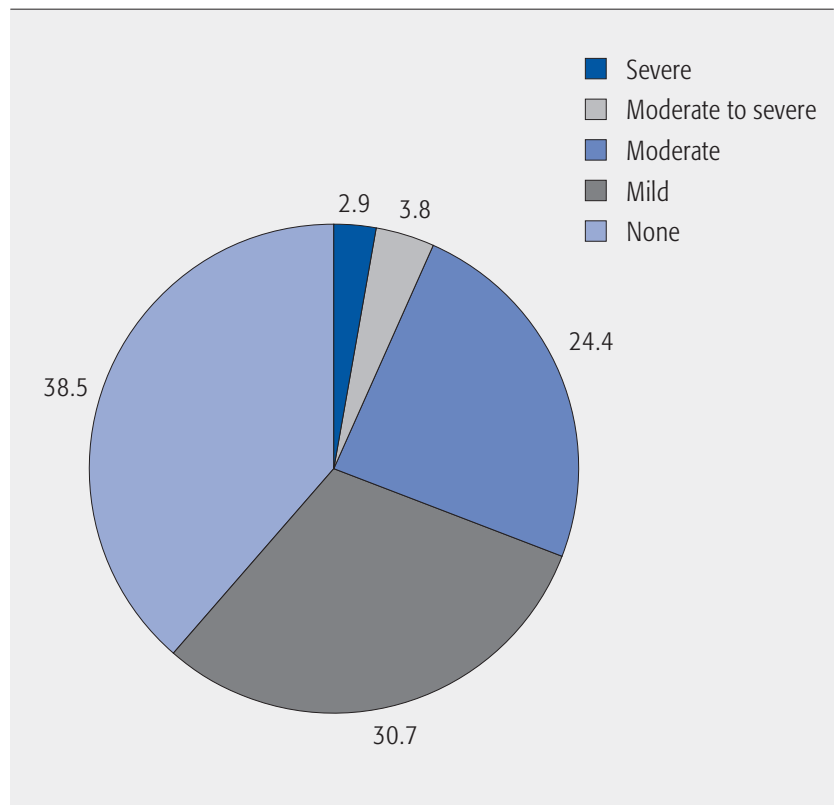

Fig 3 Current activity level-(What is your current level of work/ school activity?)

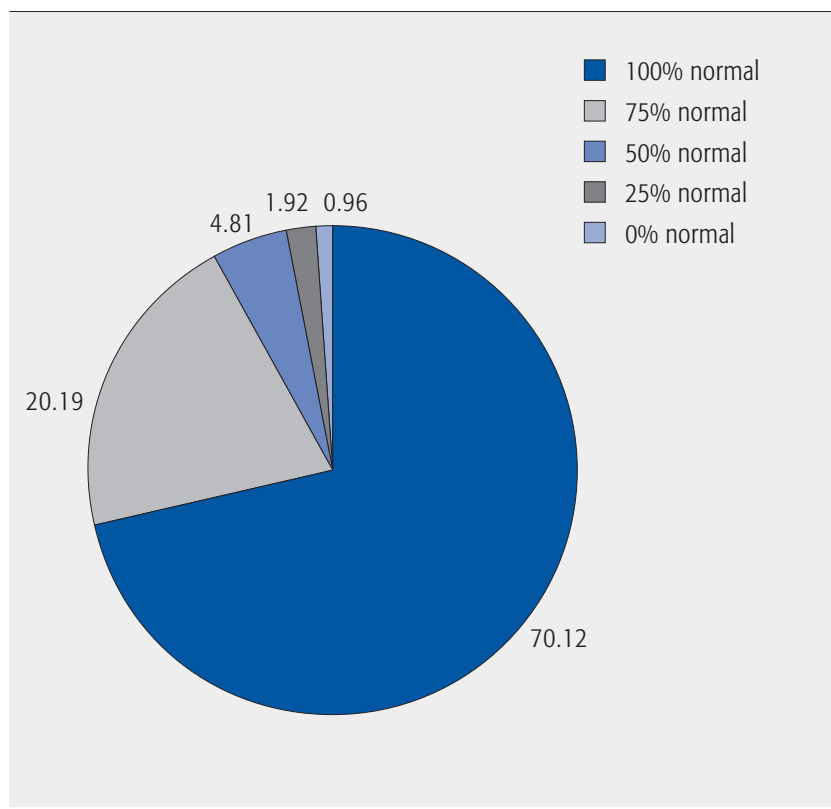

Table 2 Summary of potential risk factors for pain based on SRS Question 1: no pain versus "any" pain.

\begin{tabular}{|c|c|c|c|c|}
\hline & & No $(n=40)$ & Yes $(n=64)$ & P* \\
\hline $\begin{array}{l}\text { Patient } \\
\text { characteristics }\end{array}$ & & Mean (range) & $\begin{array}{l}\text { Mean } \\
\text { (range) }\end{array}$ & \\
\hline \multirow[t]{2}{*}{ Age, y } & At surgery & $\begin{array}{l}14.7 \\
(11.25-17.75)\end{array}$ & $15.0(12-21)$ & NS \\
\hline & At follow-up & $19.2(13-27)$ & $19.9(13-26)$ & NS \\
\hline \multirow[t]{3}{*}{ Gender } & & №. $(\%)$ & No. $(\%)$ & \\
\hline & Female & $32(35.2)$ & $59(64.8)$ & .067 \\
\hline & Male & $8(61.5)$ & $5(38.5)$ & \\
\hline \multicolumn{5}{|l|}{ Follow-up, y } \\
\hline & $\leq 2$ & $13(44.8)$ & $16(55.2)$ & .582 \\
\hline & $2-5$ & $15(39.5)$ & $23(60.5)$ & \\
\hline & $>5$ & $12(32.5)$ & $25(67.6)$ & \\
\hline \multicolumn{5}{|l|}{ Lenke curve type } \\
\hline & 1 & $19(38)$ & $31(62.0)$ & $.664^{*}$ \\
\hline & 2 & $2(40.0)$ & $3(60.0)$ & \\
\hline & 3 & $1(35.7)$ & $27(64.3)$ & \\
\hline & 4 & $1(100)$ & $0(0)$ & \\
\hline & 5 & $0(0)$ & $2(100)$ & \\
\hline \multicolumn{5}{|c|}{ Procedural factors } \\
\hline \multicolumn{5}{|l|}{ Surgical approach } \\
\hline & CSF & $6(40.0)$ & $9(60.0)$ & .895 \\
\hline & PSF & $34(38.2)$ & $55(61.8)$ & \\
\hline \multicolumn{5}{|c|}{ Lowest instrumented } \\
\hline & $\mathrm{T} 11$ & $0(0)$ & $1(100)$ & $.996 *$ \\
\hline & $\mathrm{T} 12$ & $3(37.5)$ & $5(62.5)$ & \\
\hline & $\mathrm{L} 1$ & $10(38.5)$ & $16(61.5)$ & \\
\hline & $\mathrm{L} 2$ & $10(37.0)$ & $17(63.0)$ & \\
\hline & L3 & $11(39.3)$ & $17(60.7)$ & \\
\hline & L4 & $3(30.0)$ & $7(70.0)$ & \\
\hline \multicolumn{5}{|l|}{ Instrument type } \\
\hline & TSRH & $6(37.5)$ & $10(62.5)$ & $.022^{*}$ \\
\hline & USS & $18(65.2)$ & $14(43.8)$ & \\
\hline & Colorado & $9(37.5)$ & $15(62.5)$ & \\
\hline & ISOLA & $3(50.0)$ & $3(50.0)$ & \\
\hline & Synergy & $0(0)$ & $7(100)$ & \\
\hline & Transpine & $2(14.3)$ & $12(85.7)$ & \\
\hline \multicolumn{5}{|l|}{$\begin{array}{l}\text { No. levels } \\
\text { instrumented }\end{array}$} \\
\hline & Mean (range) & $11.2(9-14)$ & $11.1(7-14)$ & NS \\
\hline \multirow[t]{9}{*}{ Complications } & & No $(n=40)$ & Yes $(n=64)$ & \\
\hline & Reoperation & $2(28.60)$ & $5(71.43)$ & $.704^{*}$ \\
\hline & Pseudarthrosis $^{\dagger}$ & $6(54.5)$ & $5(44.5)$ & $.328^{*}$ \\
\hline & Implant failure & $1(25.0)$ & $3(75.0)$ & $1.00^{*}$ \\
\hline & Correction loss $>15$ & $4(57.1)$ & $3(42.9)$ & $.425^{*}$ \\
\hline & Infection & & & \\
\hline & Superficial & $1(20.0)$ & $4(80.0)$ & $.647^{*}$ \\
\hline & Deep & $0(0)$ & $1(100)$ & $1.00^{*}$ \\
\hline & Dislodging of hook & $1(33.3)$ & $2(66.7)$ & $1.00^{*}$ \\
\hline
\end{tabular}

* NS indicates not significant. $P$ value based on two-tailed tests.

† Pseudarthrosis (includes patients who had implant failure $[n=4]$ ) and correction loss $[n=7]$ ) occurred in $10.6 \%$ of participants. 
Table 3 Results of nonparametric tests of association between SRS Pain Domain Score as the outcome variable and individual prognostic factors.

\begin{tabular}{lll}
\hline Prognostic factor & & \\
\hline Correlation & Spearman rho & $\boldsymbol{P}$ \\
\hline Age, y & & \\
- At surgery & -0.0635 & .5222 \\
- At follow-up & -0.1542 & .1182 \\
\hline Follow-up, y & -0.0774 & .4349 \\
\hline No. of instrumented levels & -0.0710 & .4824 \\
\hline Kruskall-Wallis test & $\boldsymbol{P}$ & P with ties \\
\hline Gender & .2286 & .2205 \\
\hline Lenke curve type & .4464 & .4286 \\
\hline Surgical approach & .6704 & .6649 \\
\hline Lowest instrumented level & .9560 & .9529 \\
\hline Instrumentation type & .0067 & .0052 \\
\hline Reoperation & .9122 & .9107 \\
\hline Pseudarthrosis* & .1678 & .1604 \\
\hline Implant failure & .6481 & .6423 \\
\hline Correction loss $>15^{\circ}$ & .5082 & .5007 \\
\hline Dislodging of hook & .7486 & .7443 \\
\hline Infection & & .20489 \\
\hline Superficial & .2128 & \\
\hline Deep & .5826 & \\
\hline Pseudathrosis & & \\
\hline
\end{tabular}

* Pseudarthrosis (includes patients who had implant failure $([n=4]$ and correction loss [ $n=7]$ ) occurred in $10.6 \%$ of participants.

Table 4 Summary of functional outcomes measures scores.*

\begin{tabular}{llll}
\hline & Mean (SD) & Median & Range \\
\hline SRS-22 Questionnaire Scores & & & \\
\hline SRS Total score & $94.5(10.8)$ & 97 & $58-110$ \\
\hline Pain domain & $4.3(0.75)$ & 4.6 & $1.6-5.0$ \\
\hline Mental health domain & $4.1(0.67)$ & 4.2 & $2.2-5.0$ \\
\hline Function domain & $4.6(0.46)$ & 4.6 & $2.8-5.0$ \\
\hline Self-image domain & $4(0.65)$ & 4.1 & $1.8-5.0$ \\
\hline $\begin{array}{l}\text { Satisfaction/dissatisfaction with } \\
\text { management }\end{array}$ & $4.5(0.81)$ & 5.0 & $0-5.0$ \\
\hline $\begin{array}{l}\text { Oswestry Disability Index, } \\
\text { total score (\%) }\end{array}$ & & & \\
\hline
\end{tabular}

* SRS indicates Scoliosis Research Society.

${ }^{\dagger}$ Higher scores indicate greater disability.

\section{DISCUSSION}

- We believe that describing the prevalence of pain is more relevant than evaluation of the pain domain score because it is a frequent question that patients and their families want to know before deciding whether to undergo scoliosis surgery in terms of impairment after spinal fusion.

- The prevalence of low back pain after surgery for scoliosis has been reported from $7 \%-77 \%$ in previous studies [6-8]. In our study, $61.5 \%$ of AIS patients surgically treated for AIS reported back pain at 4.8-year follow-up. This prevalence is similar to the rates reported in some mid-term studies [7, 9]. However, the prevalence of pain found in our study is lower than the rates $(73 \%-77.7 \%)$ reported in long-term studies with a minimum follow-up of 10 years $[6,10,11]$. The more favorable results of our study and others $[7,9]$ may be related to the shorter follow-up or the method of quantification.

- We agree with most of the studies that back pain after scoliosis surgery is often mild and does not produce disability in most patients [6, 8, 9, 12-14]. In support of these findings, Danielsson and Nachemson [6] described that surgically treated AIS patients showed no decrease of activity and functioned at the same level compared with controls without scoliosis.

- Tsutsui et al [15] compared the isolated effects of spinal fusion and deformity magnitude on quality of life in three cohorts of patients with AIS (preoperative, postoperative, and nonoperative). In contrast to our results, they found that spinal fusion had an isolated negative effect on AIS patients' quality of life mostly due to a decrease in scores of the activity domain. A possible explanation is that surgically treated patients usually have more fear of injury than nonoperative patients, thus inhibit their propensity toward engaging in physical activities.

- We found no correlation of the curve size and curve correction with pain and function scores. This lack of correlation has been reported in some other studies [6, 10, 13, 16]. Niemeyer et al [9] reviewed 41 patients with AIS treated with spinal fusion and Harrington instrumentation with a mean follow-up of 23 years. They found a significant correlation between the scores and the Cobb angle preoperatively. Takayama et al [13] found that positive sagittal balance at the latest followup affected degree of LBP. This finding emphasizes the importance of carefully ensuring sagittal plane alignment in the treatment of spinal deformity.

- The effect of long versus short fusion has been much discussed. In the present study, we do not find any correlation between pain and length of spinal fusion 
or the caudal level of fusion as in other studies [6, 9, $13,17]$. However, in a study of 180 patients who underwent surgery for AIS (Harrington rod), Fabry et al [18] described an increase of back pain with fusions extending to L4 or L5. Hayes et al [19] confirmed these observations. They followed-up 48 patients who underwent surgery for an average of 11 years and found a higher prevalence of low back pain in patients receiving fusion to L4 (61\%). Also, Bartie et al [11] found that low back pain intensity was slightly higher in those fused to L4 compared with those fused to L2 or L3. The patients reported in these studies received Harrington instrumentation, which applies distractive forces on the frontal and lateral planes, and flattens the physiological lumbar lordosis when applied to the lumbar spine. This loss of lordosis probably causes the early degenerative changes and consequent lumbar pain noted in these studies [11, 18, 19]. In 2000 PérezGrueso et al [12] reported on 35 patients fused to L3, L4, or L5 using Cotrel-Dubousset (CD) instrumentation with a minimum 10-year follow-up. Magnetic resonance imaging of the lumbar spine was included in the evaluation. Thirty-five-matched controls were used. They found that CD instrumentation maintained the physiological sagittal contour and there were no differences between patients and control group insofar as pain or general function was concerned.

- Instrumentation type was the only variable that was significantly associated with elevated Pain Domain Scores (PDS) in our study. We could not find any explanation for this finding. Helenius et al [14] compared long-term functional and radiographic outcomes using Harrington and Cotrel-Dubousset instrumentation in AIS. They found a substantially lower prevalence of low back pain in both groups but the prevalence tended to be lower in the Cotrel-Dubousset instrumentation group than in the Harrison instrumentation group (11\% versus $13 \%$ reported that they felt back pain often or very often). There seems to be a need for comparison and evidence of superiority of the different types of scoliosis instrumentation.

- Strengths of this study include the use of validated outcomes measures and systematic exploration of factors that may have influenced pain. We also were able to obtain a sizeable long-term follow-up cohort given the timespan of observation.

- The significant ceiling effect for the PDS (and on question one) on one hand may indicate that the highest percentage of patients had mild pain or no pain. It may, however, point to limitations of the scores' ability to discriminate across levels of pain. A marked ceiling effect for low ODI scores was noted in preliminary analysis, suggesting that overall patients had good function. This ceiling effect (and small numbers of patients in categories, such as specific curve type) precludes meaningful statistical analysis of this measure. The small sample size and possible lack of sensitivity of the ODI may have contributed to this.

- Since there are no presurgical scores for SRS to compare with those at follow-up, conclusions regarding the extent to which surgical intervention improved patient pain and function cannot be made and no conclusions regarding the proportion of individuals who attained a minimal clinically important improvement can be made.

- Selection of instrumentation type was based on surgeon preference, not deformity severity or type. Although an association between instrument type and the prevalence of pain at 6 months and the PDS was seen, unmeasured factors that contributed to the decision of what instrument to use may confound the relationship. From these data a causal inference cannot be made.

- Limitations of our study include the following factors: it is a retrospective study that left us unable to compare postoperative results with preoperative evaluations; we encountered a wide range of follow-up times; there were small numbers of patients in certain categories. There is likely limited power to detect statistical associations between some variables and the PDS due to small numbers of individuals in a given category (eg, only one person had a type 5 curve) or relatively rare events, such as deep infection.

- Given the large proportion of persons reporting normal activity, there were inadequate numbers of patients for further analysis of factors associated with disability.

\section{SUMMARY AND CONCLUSIONS}

- Overall, the high percentage (> 69\%) of individuals reporting no pain or mild pain in the past 6 months may suggest a certain level of surgical success. It may however point to limitations of SRS score to discriminate between various levels of intensity of levels of pain.

- Most patients experienced no severe impairment of their function after spinal fusion $(72.1 \%$ of participants reported a current work/school activity level of $100 \%$ normal and $20.2 \%$ reported current level of $75 \%$ normal).

- Although degenerative changes in the lumbar spine below the fusion have been a great concern among scoliosis surgeons, there was no association between pain and level of fusion in our study.

- This mid-term follow-up of spinal fusion for AIS showed no important impairment of health-related quality of life. 


\section{REFERENCES}

1. D'Andrea LP, Betz RR, Lenke LG, et al (2000) Do radiographic parameters correlate with clinical outcomes in adolescent idiopathic scoliosis? Spine (Phila Pa 1976); 25(14):17951802.

2. Wilson PL, Newton PO, Wenger DR, et al (2002) A multicenter study analyzing the relationship of a standardized radiographic scoring system of adolescent idiopathic scoliosis and the Scoliosis Research Society outcomes instrument. Spine (Phila Pa 1976); 27(17):20362040.

3. Asher M, Min Lai S, Burton D, et al (2003) The reliability and concurrent validity of the scoliosis research society-22 patient questionnaire for idiopathic scoliosis. Spine (Phila Pa 1976); 28:63-69.

4. Bago J, Climent JM, Ey A, et al (2004) The Spanish version of the SRS-22 patient questionnaire for idiopathic scoliosis: transcultural adaptation and reliability analysis. Spine (Phila Pa 1976); 29(15):1676-1680.

5. Fairbank JC, Pynsent PB (2000) The Oswestry Disability Index. Spine (Phila Pa 1976); 25(22):2940-2952; discussion 2952.

6. Danielsson AJ, Nachemson AL (2003) Back pain and function 23 years after fusion for adolescent idiopathic scoliosis: a case-control study-part II. Spine (Phila Pa 1976); 28:E373383.

7. Remes V, Helenius I, Schlenzka D, et al (2004) Cotrel-Dubousset (CD) or Universal Spine System (USS) instrumentation in adolescent idiopathic scoliosis (AIS): comparison of midterm clinical, functional, and radiologic outcomes. Spine (Phila Pa 1976); 29(18):2024-2030.

8. Helenius I, Remes V, Lamberg T, et al (2008) Long-term health-related quality of life after surgery for adolescent idiopathic scoliosis and spondylolisthesis. J Bone Joint Surg Am; 90(6):1231-1239.

9. Niemeyer T, Bovingloh AS, Grieb $S$, et al (2005) Low back pain after spinal fusion and Harrington instrumentation for idiopathic scoliosis. Int Orthop; 29(1):47-50.

10. Dickson JH, Erwin WD, Rossi D (1990) Harrington instrumentation and arthrodesis for idiopathic scoliosis: a twenty-one-year followup. J Bone Joint Surg Am; 72(5):678-683.

11. Bartie BJ, Lonstein JE, Winter RB (2009) Long-term follow-up of adolescent idiopathic scoliosis patients who had Harrington instrumentation and fusion to the lower lumbar vertebrae: is low back pain a problem? Spine (Phila Pa 1976); 34(24):E873-878.
12. Pérez-Grueso FS, Fernandez-Baillo N, Arauz de Robles S, et al (2000) The low lumbar spine below Cotrel-Dubousset instrumentation: long-term findings. Spine (Phila Pa 1976); 25(18):2333-2341.

13. Takayama K, Nakamura H, Matsuda H (2009) Low back pain in patients treated surgically for scoliosis: longer than sixteen-year follow-up. Spine (Phila Pa 1976); 34:2198-2204.

14. Helenius I, Remes V, Yrjonen T, et al (2003) Harrington and Cotrel-Dubousset instrumentation in adolescent idiopathic scoliosis: longterm functional and radiographic outcomes. $J$ Bone Joint Surg Am; 85-A(12):2303-2309.

15. Tsutsui S, Pawelek J, Bastrom T, et al (2009) Dissecting the effects of spinal fusion and deformity magnitude on quality of life in patients with adolescent idiopathic scoliosis. Spine (Phila Pa 1976); 34(18):E653-658.

16. Benli IT, Ates B, Akalin S, et al (2007) Minimum 10 years follow-up surgical results of adolescent idiopathic scoliosis patients treated with TSRH instrumentation. Eur Spine J; 16(3):381-391.

17. Helenius I, Remes V, Yrjönen T, et al (2002) Comparison of long-term functional and radiologic outcomes after Harrington instrumentation and spondylodesis in adolescent idiopathic scoliosis: a review of 78 patients. Spine (Phila Pa 1976); 27(2):176-180.

18. Fabry G, Van Melkebeek J, Bockx E (1989) Back pain after Harrington rod instrumentation for idiopathic scoliosis. Spine (Phila Pa 1976); 14(6):620-624.

19. Hayes MA, Tompkins SF, Herndon WA, et al (1988) Clinical and radiological evaluation of lumbosacral motion below fusion levels in idiopathic scoliosis. Spine (Phila Pa 1976); 13(10):1161-1167.

\section{ACKNOWLEDGMENTS}

We thank EBSJ's Enhanced Methods Support Program (EMSP) and analysis support from Spectrum Research for the revision of the work. Also we thank Grupo Español de Enfermedades del Raquis-Spanish Society of Spinal Disorders) for their support. 


\section{EDITORIAL PERSPECTIVE}

It is obvious that Bas and colleagues have put a lot of thought into this study and there are some good-quality data available. This study has a lot of potential for describing factors that may be associated with pain in the AIS population. The strength of this study is the incorporation of validated functional measures as the outcome (SRS-22 and ODI). The authors do not present much analysis of the ODI outside of a listing in Table 4 and focused on SRS-22 instead, raising the question of what role ODI played in the analysis.

The article goes a long way assuring patients with AIS and their families that there is a functional life to be had after fusion for scoliosis and that pain and disability are rare. As is the case with so many articles dealing with multiple variables and potentially confounding factors, this study raises a number of questions as well. What studies were undertaken to understand the potential causes of pain in those patients with poor outcomes? Can we be sure that these patients had no nonunions, malalignment, and prominent hardware or were suffering from indolent infection?

Did Bas and colleagues have a chance to investigate the psychosocial background of patients with poor results? Frequently, it is the insights gained from selective study of factors associated with good or insufficient outcomes that lead us to new insights. This opportunity was likely lost in this retrospective study due to the types of data gathered. All things considered, they have substantially advanced our understanding of AIS surgery and its implications on patient outcomes and deserve our praise. 